\title{
Pattern of Impacted Mandibular Third Molar in Patients Presenting to Tertiory Core Hospital in Chitwan, Nepal
}

\author{
Dr Ashutosh Kumar Singh,' Dr Safal Dhungel² \\ 'Assistant Professor, ${ }^{2}$ Lecturer, Department of Oral \& Maxillofacial surgery \\ College of Medical Sciences, Bharatpur, Chitwan, Nepal
}

Correspondence: Dr Ashutosh Kumar Singh; Email: drashutoshkumarsingh@gmail.com

\section{ABSTRACT}

Introduction: Impacted third molars are a major cause of visit to the oral surgeon and are associated with various complications like pain, inflammation of associated soft tissue and trismus leading to a need for their surgical removal. They are widely classified on the basis of angulation, depth and position as evident from orthopantomogram however they present in a diverse panorama of patterns each presenting different level of difficulty and different techniques for their removal. Our study describes different pattern of impacted lower third molars and perform brief literature review of dental and skeletal implications of impacted third molars.

Materials \& Method: A retrospective study was designed in which 401 orthopantomogram were examined and the sex of patient, side of impaction and winters angulation based classification, depth and position classification as given by Pell and Gregory were recorded. Descriptive data analysis was performed with SPSS version 24 software.

Result: Out of total number of impactions 191(47.6\%) were in females and 210(52.4\%) were in males. Right sided impaction was seen in $199(49.6 \%)$ cases and $202(50.4 \%)$ were seen on left side. Mesioangular impaction was most common $203(50.6 \%)$ followed by distoangular $97(24.2 \%)$, horizontal 51 (12.7\%) and vertical $17(4.2 \%)$. Most common depth level of impaction was level I with 203(50.6\%) followed by level II 178(44.4\%) and level III 20(5\%). Most common position was position B 355(88.5\%) followed by position A $43(10.7 \%)$ and position C $3(0.7 \%)$. The most common pattern was IB ( $n=170)$ and IIB $(n=166)$.

Conclusion: The most common impaction is mesioangular followed by distoangular and horizontal.Most of the impacted third molars are in moderately difficult position.

Keywords: Classification, Impacted mandibular third molar, Orthodontic implications.

\section{INTRODUCTION}

Impaction of tooth presents a clinical scenario where the tooth does not reach its intended final position in oral cavity and is not expected to do so after end of eruption age.' There is a growing tendency of third molars to not erupt and become impacted in today's world. There are many theories regarding etiopathogenesis which suggest genetic cause, decreasing functional load on the jaw and lack of space in a mandible that is decreasing in size due to diminished stimulus from processed and soft diet. ${ }^{2}$ Of all third molars, mandibular third molars are the most commonly impacted and seen in clinics by an oral surgeon. The reason being their dependent position as compared to maxillary third molar leading to food accumulation in surrounding gingival flap and consequential pericoronitis. ${ }^{3}$ These impacted teeth present a diverse panorama of presentation radiographically. They have been classified by winters et al according to the angulation made by the long axis of third molar to the second molar and are mesioangular, vertical, horizontal, distoangular and others. ${ }^{4}$ Pell and Gregory classified them according to the relative depth of third molar to the second molar and also according to the space available for the third molar crown to erupt distal to the second molar. These three classification types can occur in a diverse combination of angulation, depth and space available. ${ }^{5}$ Various skeletal and dental features are associated with higher incidence of mandibular third molar impactions. ${ }^{6}$ Impacted mandibular third molars have also been implicated in late crowding of anterior mandibular teeth and relapse of orthodontic correction of mandibular crowding. ${ }^{7}$ In this study we have provided a descriptive cross sectional data on pattern of impacted mandibular third molars as related to sex and side of impaction with angulation, depth, space available.

\section{MATERIALS AND METHOD}

Total 401 Orthopantomogram were included in the study. Sex of the patient and side of impaction were obtained from OPG record. Orthopantomogram was 
performed for each case on a Gendex panoramic x-ray system. All impactions were classified according to Winters angulations classification as calculated from Orthopantomogram by tracing the long axis of third molar and the second molar and angle between them was calculated by the Orthoralix Vixwin software. ${ }^{8}$

\begin{tabular}{|c|c|}
\hline Classification & Angle in degrees \\
\hline Mesioangular & 11 to 79 \\
\hline Vertical & -10 to 10 \\
\hline Horizontal & 80 to 100 \\
\hline Distoangular & -11 to -79 \\
\hline
\end{tabular}

Pell and Gregory Depth classification was done by tracing the occlusal level of third molar against the long axis of second molar on same software. Pell and Gregory space availability were calculated by measuring space available distal to second molar and anterior to anterior border of ramus and mesiodistal width of third molar after which the difference was calculated by the software. positive difference value was categorized as Class I, 0 value as Class II and negative value as Class III. ${ }^{6}$

\section{Pell and Gregory depth classification}

\begin{tabular}{|c|l|}
\hline Classification & \multicolumn{1}{c|}{ Depth position } \\
\hline Level A & $\begin{array}{l}\text { Highest point of third molar at the same } \\
\text { level as occlusal level of second molar }\end{array}$ \\
\hline Level B & $\begin{array}{l}\text { Highest point of third molar below the } \\
\text { occlusal level but above cervical line he of } \\
\text { second molar }\end{array}$ \\
\hline Level C & $\begin{array}{l}\text { Highest point of third molar below the } \\
\text { cervical line of second molar }\end{array}$ \\
\hline
\end{tabular}

Pell and Gregory Space availability classification

\begin{tabular}{|c|l|}
\hline Classification & \multicolumn{1}{|c|}{ Space available } \\
\hline Class I & $\begin{array}{l}\text { space between distal surface of second } \\
\text { molar and anterior ramus is more than } \\
\text { mesiodistal width of the third molar and the } \\
\text { third molar is present completely anterior to } \\
\text { the ramal bone }\end{array}$ \\
\hline \multirow{3}{*}{ Class II } & $\begin{array}{l}\text { space between distal surface of second } \\
\text { molar and anterior ramus is less than } \\
\text { mesiodistal width of the third molar thereby } \\
\text { the third molar is partially embedded in the } \\
\text { ramal bone }\end{array}$ \\
\hline Class III & $\begin{array}{l}\text { space between distal surface of second } \\
\text { molar and anterior ramus and the third } \\
\text { molar is completely embedded in ramal } \\
\text { bone }\end{array}$ \\
\hline
\end{tabular}

\section{RESULT}

Results were calculated with SPSS version 24 for mac (IBM corp. SPSS statistics). Descriptive studies were used to observe distribution of pattern of impaction and difficulty index with sex and side of impaction. total number of impactions $191(47.6 \%)$ were in females and $210(52.4 \%)$ were in males (Table 1). Right sided impaction was seen in $199(49.6 \%)$ cases and $202(50.4 \%)$ were seen on left side. (Table 2)

Mesioangular impaction was most common 203(50.6\%) followed by distoangular 97(24.2\%), horizontal 51(12.7\%) and vertical 17(4.2\%) (Table 3). Most common depth level of impaction was level I with 203(50.6\%) followed by level II 178(44.4\%) and level III 20(5\%). Most common position

Table 1: Sex distribution of impacted mandibular third molars

\begin{tabular}{|c|c|c|}
\hline Gender & Frequency & Percent \\
\hline Female & 191 & 47.6 \\
\hline Male & 210 & 52.4 \\
\hline Total & 401 & 100.0 \\
\hline
\end{tabular}

Table 2: Side distribution of impacted mandibular third molars

\begin{tabular}{|c|c|c|}
\hline Side & Frequency & Percent \\
\hline Right & 199 & 49.6 \\
\hline Left & 202 & 50.4 \\
\hline Total & 401 & 100.0 \\
\hline
\end{tabular}

Table 3: Angulation distribution of impacted mandibular third molars

\begin{tabular}{|c|c|c|}
\hline Winters classification & Frequency & Percent \\
\hline Mesioangular & 236 & 58.9 \\
\hline Vertical & 17 & 4.2 \\
\hline Horizontal & 51 & 12.7 \\
\hline Distoangular & 97 & 24.2 \\
\hline Total & 401 & 100.0 \\
\hline
\end{tabular}


Table 4: Depth distribution of impacted mandibular third molars

\begin{tabular}{|c|c|c|c|}
\hline \multirow{2}{*}{ Depth } & \multicolumn{3}{|c|}{ Position } \\
\cline { 2 - 4 } & A & B & C \\
\cline { 2 - 4 } & Count & Count & 2 \\
\hline Level I & 31 & 170 & 0 \\
\hline level II & 12 & 166 & 1 \\
\hline level III & 0 & 19 & 19 \\
\hline
\end{tabular}

Table 5: Difficulty Index distribution of impacted mandibular third molars

\begin{tabular}{|c|c|c|}
\hline & Frequency & Percent \\
\hline Mild Difficulty & 107 & 26.7 \\
\hline Moderate difficulty & 266 & 66.3 \\
\hline Very difficult & 28 & 7.0 \\
\hline Total & 401 & 100.0 \\
\hline
\end{tabular}

Table 6: Association between gender and angulation of Impaction

\begin{tabular}{|c|c|c|c|c|}
\hline \multirow{2}{*}{ Gender } & \multicolumn{3}{|c|}{ winters } \\
\cline { 2 - 5 } & mesioangular & Vertical & horizontal & distoangular \\
\cline { 2 - 5 } & Count & Count & Count & 51 \\
\hline Female & 106 & 2 & 32 & 46 \\
\hline Male & 130 & 15 & 19 & 46 \\
\hline
\end{tabular}

Table 7: Distribution of position and depth of impaction with gender

\begin{tabular}{|c|c|c|c|c|c|c|c|c|c|}
\hline \multirow{5}{*}{ Gender } & \multicolumn{9}{|c|}{ Position } \\
\hline & \multicolumn{3}{|c|}{ A } & \multicolumn{3}{|c|}{ B } & \multicolumn{3}{|c|}{ C } \\
\hline & \multicolumn{3}{|c|}{ depth } & \multicolumn{3}{|c|}{ depth } & \multicolumn{3}{|c|}{ depth } \\
\hline & Level I & level II & level III & Level I & level II & level III & Level I & level II & level III \\
\hline & Count & Count & Count & Count & Count & Count & Count & Count & Count \\
\hline Female & 11 & 9 & 0 & 87 & 79 & 4 & 1 & 0 & 0 \\
\hline Male & 20 & 3 & 0 & 83 & 87 & 15 & 1 & 0 & 1 \\
\hline
\end{tabular}

was position B 355(88.5\%) followed by position A 43(10.7\%) and position C $3(0.7 \%)$. The most common pattern was IB $(n=170)$ and IIB ( $n=166)$ (Table 4). On Pederson's difficulty index $66.3 \%$ presented as moderately difficult, $26.7 \%$ as mildly difficult and $7 \%$ as very difficult. (Table 5)

Mesioangular impactions were most common among male and female (Table 6). Pell and Gregory pattern IB and II B was found to be most common in both male and females (Table 7). Most impactions fell into the moderate difficulty level among males and females as well as sides. Both left and right side had similar difficulty index and no significant difference was found among gender and sides.

\section{DISCUSSION}

The study is first descriptive study to be conducted on types of Impacted mandibular third molar in Chitwan district. Our results show a slight predilection of male gender and left side. Similar studies have contrary results that show more female prevalence in a study done in Dhulikhel. ${ }^{10}$ Venta, et al. and Qirreish reported that there were more females than males who presented with impacted mandibular third molars. ${ }^{11,12}$

Mesioangular angulation was the most common classification in our study which is similar to the findings from two previous studies in Nepal. Similar findings have been reported in most of the studies and the rotation from a horizontal to a vertical position during development of third molar has been attributed to the mesioangular angulation being most common form of impacted mandibular third molars. ${ }^{13-16}$

Most common form of ramus relationship in our study was position B and the most common depth was level I. Similar findings have been reported by other studies.

Evaluation of Pederson difficulty Index in our study shows that most common difficulty level is Moderate followed by mildly difficult. Many clinical trials and a systematic review have questioned the predictive value of Pederson difficulty index in real clinical scenarios but it is still a valuable tool for initial evaluation of impacted third molars. ${ }^{17}$ 
In our study, the most common pattern of depth and ramus space was seen as IB and IIB. No significant difference was seen among gender and sides. Difficulty was also statistically similar among gender and sides.

There are many skeletal and dental features associated with higher incidence of impacted mandibular third molars. Less than ideal posterior space for eruption, less resorption at anterior border of ramus and general posteriorly directed force of eruption of dentition are implicated for impaction of tooth. Less mandibular horizontal growth, vertically directed condylar growth and vertical growth pattern of mandible are associated with higher incidence of impactions. ${ }^{18,19}$

There has been a long discussed controversy regarding the role of impacted mandibular third molars on delayed anterior dental crowding and relapse of orthodontic treatment. Some authors implicated the anterior directed force and resulting mesial drift of the dentition was caused by pressure from an impacted mandibular third molar continuously exerting an anteriorly directed force. ${ }^{20}$ This theory was analyzed with longitudinal studies which failed to show any significant difference in development of malocclusion and presence of impacted mandibular third molars. ${ }^{21,22}$ Furthermore, studies have proved that the anteriorly directed force on dentition is present even in absence of impacted third molars and is supposed to be the effect of occlusal inclination and masticatory forces during function. Multiple current systematic reviews have concluded that there is no conclusive evidence to associate impacted mandibular third molars with anterior dental crowding and relapse of orthodontic treatment and hence prophylactic surgical removal is not advocated. ${ }^{23,24}$

One other issue regarding impacted third molars is their possible role as substitute for a non-salvageable second or first molars. In extraction cases for space management during orthodontic treatment, there is strong evidence suggesting that favorable eruption and alignment of third molars are seen in these cases. ${ }^{25}$ Thus, it has been suggested that in cases where premolars have been extracted for orthodontic treatment, seemingly impacted mandibular third molars should be treated conservatively as they more than often end up in good position and alignment and might act as substitutes in cases where first or second molars are not salvageable. ${ }^{26-28}$

Another issue is when there is planned orthodontic movement of molars distally to gain space. The Impacted third molars tend to act as center of resistance and significantly slow down the posterior movement of tooth sometimes even necessitating the use of extraoral implant based anchorage and force. It is imperative to say that in such cases frequent removal of impacted third molar will allow desired and predictable movement in less amount of time and thus should be consideration during treatment planning between the orthodontist and the oral surgeon. ${ }^{29,30}$

\section{CONCLUSION}

Our study presents descriptive data on pattern of mandibular impacted third molars based on OPG radiograph and the results are similar to other studies performed in Nepal as well as other countries. Prophylactic removal of impacted third molars have no sound backing evidence and there are no evidence implicating them in anterior dental crowding and relapse of orthodontic treatment. On the contrary, they can act as substitutes for molars and tend to erupt in good alignment and position in extraction cases, hence should be preserved.

\section{Limitations}

This study sample was taken from a single tertiary care hospital unit and a small sample size limits the inferential capacity of the study. A multicenter study with large sample size should be planned in the future. 


\section{REFERENCES}

1. Carter K, Worthington S. Predictors of Third Molar Impaction: A Systematic Review and Meta-analysis. Journal of Dental Research 2016:95:267-76.

2. Poznań, Poland, Kropielnicki K, Department of Oral Surgery and Periodontology, Poznan University of Medical Sciences, Poznań, Poland, et al. Extraction of asymptomatic impacted third molars - a review. European Journal of Clinical and Experimental Medicine 2019;17:71-8.

3. Campbell JH. Third Molar Pericoronitis. Journal of Oral and Maxillofacial Surgery 2016;74:2122.

4. Winter GB. Principles of exodontia as applied to the impacted mandibular third molar a complete treatise on the operative technic with clinical diagnoses and radiographic interpretations. vol. 1. First. St. Louis: American medical book company; 1926.

5. Peterson L, III Ellis E, Hupp K, Tucker M. Contemporary Oral and Maxillofacial surgery . vol. 1. 3rd ed. St. Louis : Mosby; 1998.

6. Pell GJ, Gregory GT. Report on a ten-year study of a tooth division technique for the removal of impacted teeth. American Journal of Orthodontics and Oral Surgery 1942;28:B660-6.

7. Bali A, Bali D, Sharma A, Verma G. Is Pederson Index a True Predictive Difficulty Index for Impacted Mandibular Third Molar Surgery? A Meta-analysis. Journal of Maxillofacial and Oral Surgery 2013;12:359-64.

8. Quek SL, Tay CK, Tay KH, Toh SL, Lim KC. Pattern of third molar impaction in a Singapore Chinese population: a retrospective radiographic survey. International Journal of Oral and Maxillofacial Surgery 2003;32:548-52.

9. Park K-L. Which factors are associated with difficult surgical extraction of impacted lower third molars? Journal of the Korean Association of Oral and Maxillofacial Surgeons 2016:42:251.

10. Upadhyay C, Chaurasiya N. Comparative Study to Determine the efficacy of Zinc Oxide Eugenol and Alveogyl in Treatment of Dry Socket KUMJ 2017:57:67-70.

11. Gbotolorun OM, Olojede ACO, Arotiba GT, Ladeinde AL, Akinwande JA, Bamgbose BO. Impacted mandibular third molars: Presentationn and postoperative complications at the Lagos University Teaching Hospital. Nigerian Quarterly Journal of Hospital Medicine 2007;17:2629-29.

12. Ventä I, Turtola L, Ylipaavalniemi P. Radiographic follow-up of impacted third molars from age 20 to 32 years. International Journal of Oral and Maxillofacial Surgery 2001;30:54-7.

13. Qirreish EEYJ. Radiographic profile of symptomatic impacted mandibular third molars in the Western Cape, South Africa. Thesis. University of the Western Cape, 2005.

14. Ren CGC, Senthil Kumar B. Prevalence of Eruption of Third Molar Tooth among South Indians and Malaysians. Journal of Academy of Dental Education 2014;1:32.

15. Hassan A. Pattern of third molar impaction in a Saudi population. Clinical, Cosmetic and Investigational Dentistry 2010:109. doi:10.2147/ CCIDEN.S12394.

16. Sandhu S, Kaur T. Radiographic Evaluation of the Status of Third Molars in the Asian-Indian Students. Journal of Oral and Maxillofacial Surgery 2005;63:640-5.

17. Kharma MY, Sakka S, Aws G, Tarakji B, Nassani MZ. Reliability of Pederson Scale in Surgical Extraction of Impacted Lower Third Molars: Proposal of New Scale. Journal of Oral Diseases 2014;2014:1-4.

18. Björk A, Jensen E, Palling M. Mandibular growth and third molar impaction. Acta Odontol Scand 1956; 14: 231-272

19. Capelli J. Mandibular growth and third molar impaction in extraction cases. Angle Orthod 1991; 61: 223-229 [PMID: 1928824]

20. Bergström K, Jensen R. Responsibility of the third molar for secondary crowding. Dent Abstr 1961; 6:544

21. Southard TE, Southard KA, Weeda LW. Mesial force from unerupted third molars. Am J Orthod Dentofacial Orthop 1991; 99 : $220-225$

22. Karasawa LH, Rossi AC, Groppo FC, Prado FB, Caria PH. Cross- sectional study of correlation between mandibular incisor crowding and third molars in young Brazilians. Med Oral Patol Oral Cir Bucal 2013; 18: e505-e509

23. Costa MG, Pazzini CA, Pantuzo MC, Jorge ML, Marques LS. Is there justification for prophylactic extraction of third molars? A systematic review. Braz Oral Res 2013; 27: 183-188

24. Sidlauskas A, Trakiniene G. Effect of the lower third molars on the lower dental arch crowding. Stomatologija 2006; 8: 80-84

25. Rindler A. Effects on lower third molars after extraction of second molars. Angle Orthod 1977; 47: 55-58

26. Cavanaugh JJ. Third molar changes following second molar extractions. Angle Orthod 1985; 55: 70-76

27. Staggers JA, Germane N, Fortson WM. A comparison of the effects of first premolar extractions on third molar angulation. Angle Orthod 1992; 62: 135-138

28. Jain S, Valiathan A. Influence of first premolar extraction on mandibular third molar angulation. Angle Orthod 2009; 79: $1143-1148$

29. Almpani K, Kolokitha OE. Role of third molars in orthodontics. World J Clin Cases. 2015;3(2):132-140.

30. Oshagh M, Nasrabadi NI. Relationship of third molar movement during orthodontic treatment and root angulation. Indian J Dent Res 2012;23:795-800 